\title{
Effect of Recycled Rubber Particles and Silica on Tensile and Tear Properties of Natural Rubber Composites
}

\author{
Velu CHANDRAN ${ }^{1}$, Thomas MANVEL RAJ ${ }^{1}$, Thangavelu LAKSHMANAN ${ }^{2}$ \\ ${ }^{1}$ Sri Krishna Engineering College, Chennai-601301, India \\ ${ }^{2}$ Department of Mechanical Engineering, SA Engineering College, Chennai-600077, India \\ cross $^{\text {ref }}$ http://dx.doi.org/10.5755/j01.ms.22.2.7330
}

Received 16 June 2014; accepted 06 March 2015

\begin{abstract}
Application of scrap rubber and worn out tires in natural rubber compounds has been studied. The scrap rubber can, however, be recycled and compounded with natural rubber and thus can be generated as a rubber composite. In this work, recycled rubber particles (RRP) were prepared using pulverization process. Then, RRP was blended with natural rubber and silica compounds, and it was synthesized by two- roll mill and hydraulic press at specified operating conditions. The samples ranging from 0 to $40 \mathrm{phr}$ of RRP loaded with silica were used as constant filler. The mechanical properties and morphological analysis were carried out. The results showed that tensile strength and elongation at break gradually decreased with increasing RRP loading in natural rubber and silica compounds. Tensile modulus went down at $10 \mathrm{phr}$ of RRP and then showed an increasing trend. Hardness increased up to $30 \mathrm{phr}$ of RRP and tear strength increased up to $20 \mathrm{phr}$ of RRP. A comparative study was also carried out with virgin natural rubber vulcanizates. The incorporation of RRP and silica up to $20 \mathrm{phr}$ in natural rubber did not lower the performance of rubber articles. Morphological studies revealed that better filler dispersion, interfacial adhesion, and cross link density could increase the tensile and tear strengths.

Keywords: rubber, natural rubber, recycled rubber particles, mechanical properties, silica, rubber composite.
\end{abstract}

\section{INTRODUCTION}

Natural rubber (NR) is an elastomer, which is originally derived from latex, a milky colloid mainly obtained from the plant called Hevea Brasvilenesis. The purified form of natural rubber is essentially $100 \%$ cis-1,4-polyisoprene, and this conformation leads to a number of useful mechanical properties such as improved mechanical strength on stretching [1]. The environmental pollution occurs due to so many things, specifically, scrap rubber, worn out tires, and tubes etc. These can be powered by mechanical process; it is a more suitable method of reclaiming the waste rubber than that of chemical process; then the recycled rubber powder (RRP) could be used as a filler material in the natural rubber compounds [2]. The Scrap rubber particles(SRP) composite shows the poor adhesion between the matrix and SRP; the large particles of SRP weaken the mechanical properties of the rubber composite and the unbounded SRP ones cause maximum principal stress occurring at the equatorial interface, which leads to crack propagation and decisive failure of the composite [3]. The tensile strength, permanent elongation, and hardness of NR and RRP compound show no significant changes that occur when carbon black is replaced by RRP (up to $15 \%$ ) and this compound is not recommended for tear resistance since it leads to significant reduction in tearing forces [4]. Moreover, NR and RRP compound results show that tensile properties increase with increasing recycled rubber powder loading, but elongation at break shows a decreasing trend [5]. The addition of reinforcing fillers increases tear strength,

\footnotetext{
* Corresponding author. Tel.: +91-9710881612; fax: 044-26493385

E-mail address: chandran1979mt@gmail.com (V. Chandran)
}

modulus, tensile strength, and abrasion resistance of NR composite. The dispersion state of filler determines the final properties of composites, which gives improved mechanical properties [6]. The SiC nano particles and natural rubber show excellent mechanical properties in contrast to single walled carbon nano tube-natural rubber, which shows the importance of silica addition [7]. Generally, conventional fillers like silica or carbon black are added into the rubber, approximately $13-17$ mass $\%$ of the filler, to achieve the desired reinforcing strength/ effect $[8,9]$. Rubber's ability to exhibit excellent tensile properties makes it ideal for many rubber applications [10]. Many studies have demonstrated that mechanical properties of such blends can be significantly improved by adding suitable compatibilizers [11]. In order to obtain natural rubber compounds with satisfactory mechanical properties, good dispersion of proper compatibilizer in the rubber matrix should be achieved [12-14]. The partial replacement of active fillers (silica/carbon black) with ground tire rubber (GTR) has a favorable influence on the mechanical properties [15]. Most of the earlier investigators had not considered Silica as a filler material for the natural rubber/RRP compounds for studies involving them [16]. The main purpose of this study is to investigate the effect of RRP blended with natural rubber and silica compounds on the mechanical properties that lead to better utilization of the waste tires and scrap rubber.

\section{EXPERIMENTAL}

\subsection{Materials}

Natural rubber (RMA-1X) was provided in the dry sheet form by Subbu natural rubber industrial Co., Ltd at Kerala, India. Nano silica particles $(10 \mathrm{~nm})$ were 
purchased from Lab Chemicals at Chennai, India. Worn out tires were obtained from local shops and they were crushed into fine particles $(125-250 \mu \mathrm{m})$ by using pulverization process. Curing accelerators such as sulphur, CZ accelerator, TMTD (Tetra Methyl Thiuram Disulfide), zinc oxide, aromatic oil, and stearic acid etc., are customarily used in rubber industry.

\subsection{Processing of rubber compounds}

Rubber compounds were prepared in an open two-roll mill at room temperature $\left(28^{\circ} \mathrm{C}\right)$. Initially, natural rubber was introduced to the two-roll-mill machine, which pressed and transformed it into thin and smooth forming rubber sheet round one of the rolls, rotated at $40 \mathrm{rpm}$, for the duration of $(4-5 \mathrm{~min}$.), $1.5 \mathrm{~mm}$ nip gap and the sequence of ingredients were kept the same for all the compounds. The natural rubber compound ratio and the ingredients were considered based on the data given in Table 1.

Natural Rubber Composites (NRC) samples were prepared in six proportions in terms of RRP loading ranges $0,10,20,25,30$, and 40 in phr with the addition of NR vulcanizates (NR gum) prepared. After processing tworoll-mill techniques, the rubber sheet samples were put into the flat die kit and subjected to the hydraulic press with the cup being located at the centre of the bottom platen. The rubber sheet was subjected to the following conditions for curing: temperature $160{ }^{\circ} \mathrm{C}$ and pressure $12.95 \mathrm{MPa}$ in an electrically heated hydraulic press for a duration of $3 \mathrm{~min}$. The mixing process was carried out in a conventional laboratory at Supreme rubber industry, Coimbatore, India.

\subsection{Mechanical testing}

Tensile properties tests and tear test were performed at room temperature on a universal testing machine (INSTRON 3382) at the cross-head speeds of 550 $\mathrm{mm} / \mathrm{min}$. The dumb bell and angle shaped specimens were prepared according to ASTM D-412 and ASTM D-624 respectively and then, button shaped specimens were tested for hardness based on ASTM D-2240. Hardness was tested using a Durometer (DURO TECH, model M202) shore hardness tester. The NRC samples thus obtained were subjected to various mechanical tests at CIPET, Chennai, India.

Table 1. Natural rubber composite formulation

\subsection{Morphological study}

Scanning electron microscopy (SEM) model Zeiss SUPRA 35VP FESEM was used to study the fracture surface of RRP-silica filled rubber compounds. All samples, before being scanned by the SEM, were given sputter coating with gold to avoid poor resolution and electrostatic charging.

\section{RESULTS AND DISCUSSION}

\subsection{Mechanical properties}

The above mentioned NRC samples were used in the various mechanical testing to determine tensile strength, elongation at break, tensile modulus, hardness, and tear strength. Normally, 5 samples (s1, s2, s3, s4, s5) were subjected to testing and the average value recorded has been shown in Table 2. Besides, scattered data of all the samples for tensile strength are plotted in Fig. 1.

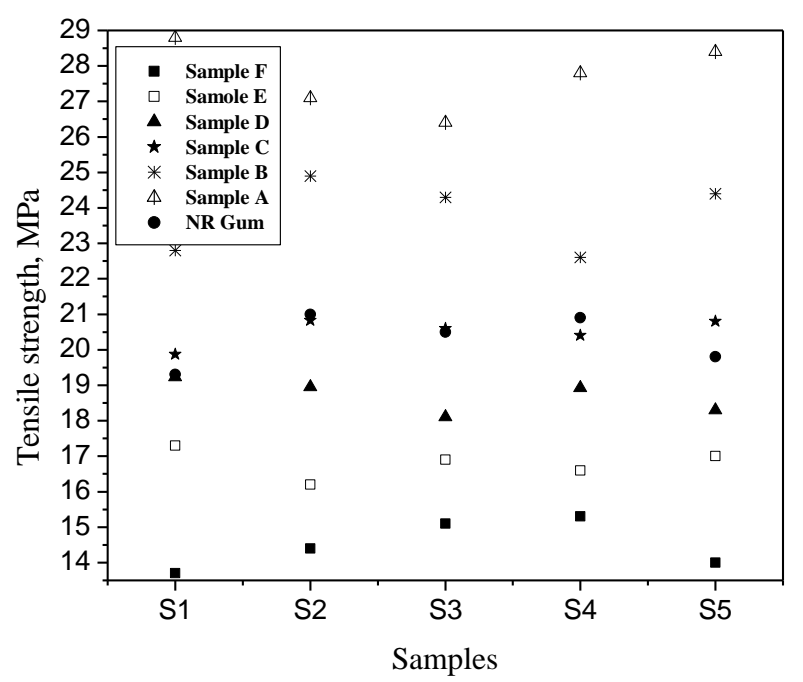

Fig. 1. Scattered data for tensile strength (all samples)

The tensile strength gradually decreased with addition of RRP in natural rubber and silica compounds as shown in Fig. 2. It was due to the discontinuous and imperfect crosslink between the RRP and rubber matrix but, the interfacial adhesion of rubber compounds did not get much weakened due to the presence of silica. NR gum exhibited identical as $20 \mathrm{phr}$ of RRP. Addition of $20 \mathrm{phr}$ of RRP/Si in NR did not reduce the performance of rubber article.

\begin{tabular}{|c|c|c|c|c|c|c|c|}
\hline \multirow{2}{*}{ Ingredients } & \multicolumn{7}{|c|}{ Sample Proportion (Phr) } \\
\hline & $\mathrm{NR} \operatorname{gum}(\mathrm{O})$ & A & $\mathrm{B}$ & $\mathrm{C}$ & $\mathrm{D}$ & $\mathrm{E}$ & $\mathrm{F}$ \\
\hline Natural Rubber & 100 & 100 & 100 & 100 & 100 & 100 & 100 \\
\hline RRP & 0 & 0 & 10 & 20 & 25 & 30 & 40 \\
\hline Silica & 0 & 20 & 20 & 20 & 20 & 20 & 20 \\
\hline Zinc oxide & 5 & 5 & 5 & 5 & 5 & 5 & 5 \\
\hline Steric acid & 2 & 2 & 2 & 2 & 2 & 2 & 2 \\
\hline Sulphur & 3 & 3 & 3 & 3 & 3 & 3 & 3 \\
\hline $\mathrm{CZ}$ & 0.9 & 0.9 & 0.9 & 0.9 & 0.9 & 0.9 & 0.9 \\
\hline $\mathrm{B}$ rods & 1 & 1 & 1 & 1 & 1 & 1 & 1 \\
\hline TMTD & 0.3 & 0.3 & 0.3 & 0.3 & 0.3 & 0.3 & 0.3 \\
\hline Aromatic oil & 3 & 3 & 3 & 3 & 3 & 3 & 3 \\
\hline
\end{tabular}


Table 2. Recorded mechanical properties with standard error

\begin{tabular}{|l|c|c|c|c|c|c|c|c|}
\hline \multirow{2}{*}{ Mechanical properties } & \multirow{2}{*}{ Methodology } & \multicolumn{9}{c|}{ Mean value of all samples } \\
\cline { 3 - 9 } & & O & A & B & C & D & E & F \\
\hline Tensile strength, MPa & ASTMD-412 & $20.3 \pm 0.33$ & $27.7 \pm 0.43$ & $23.8 \pm 0.46$ & $20.5 \pm 0.18$ & $18.7 \pm 0.21$ & $16.8 \pm 0.19$ & $14.5 \pm 0.31$ \\
\hline Elongation at break, \% & ASTMD-412 & $710 \pm 9$ & $719 \pm 10$ & $662 \pm 8$ & $642 \pm 7$ & $630 \pm 8$ & $603 \pm 7$ & $590 \pm 7$ \\
\hline Tensile modulus, MPa & ASTMD-412 & $0.49 \pm 0.03$ & $0.96 \pm 0.05$ & $1.18 \pm 0.04$ & $1.27 \pm 0.03$ & $1.47 \pm 0.04$ & $1.67 \pm 0.04$ & $2.06 \pm 0.04$ \\
\hline Hardness (Shore A) & ASTMD-2240 & $50 \pm 0$ & $54 \pm 1$ & $56 \pm 1$ & $59 \pm 1$ & $62 \pm 2$ & $63 \pm 2$ & $60 \pm 1$ \\
\hline Tear strength, MPa & ASTMD-624 & $4.51 \pm 0.19$ & $3.93 \pm 0.12$ & $5.43 \pm 0.2$ & $5.98 \pm 0.17$ & $5.55 \pm 0.15$ & $4.02 \pm 0.12$ & $3.13 \pm 0.14$ \\
\hline
\end{tabular}

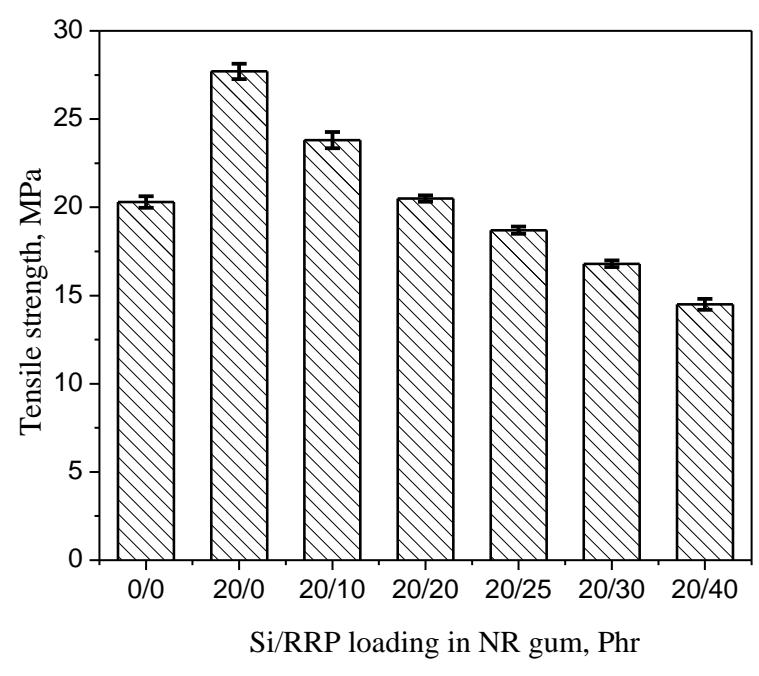

Fig. 2. Effect of tensile strength variation with RRP loading

This observation was more significant and higher compared with that of Shuyan et al reported earlier [17].

Elongation at break (\%) showed a decreasing trend as shown in Fig. 3. It was due to the RRP improperly dispersed in the silica and rubber matrix, and it resulted in imperfect structure in the compounds. Besides, cross link chains were not coupled between the RRP and rubber matrix. A similar observation had been reported [17, 18]. NR gum exhibited not much higher variation with the $20 \mathrm{phr}$ of RRP.

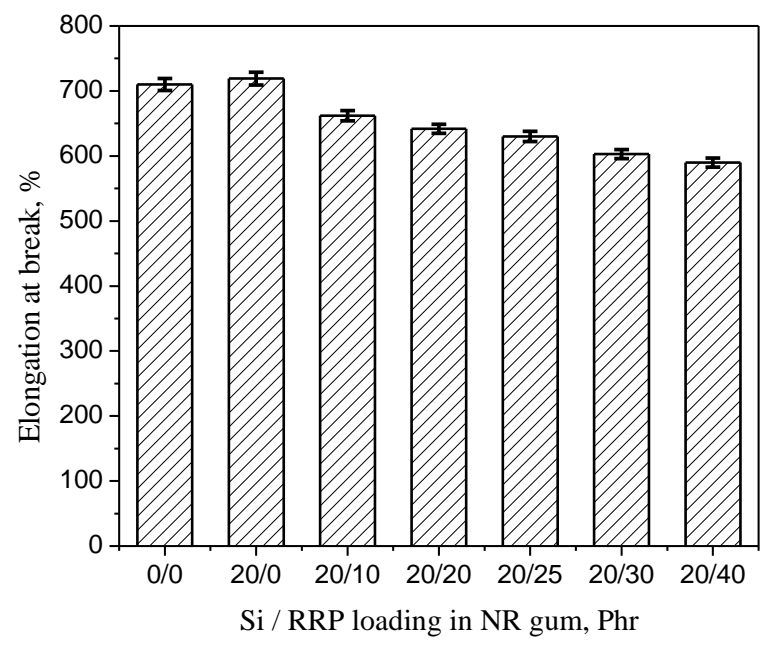

Fig. 3. Effect of elongation at break variation with RRP loading

Tensile modulus at $100 \%$ elongation (M100) is shown in Fig. 4. It can be seen that addition of rubber particles in NR-Si compounds causes tensile modulus to increase gradually. It was due to Silica particles tending to agglomerate in the interfaces of RRP and rubber matrix and consequently increasing the cross link density in the matrix. This observation was quite in agreement with the reports $[2,9]$. NR gum showed very less tensile modulus when compared with $20 \mathrm{phr}$ of RRP.

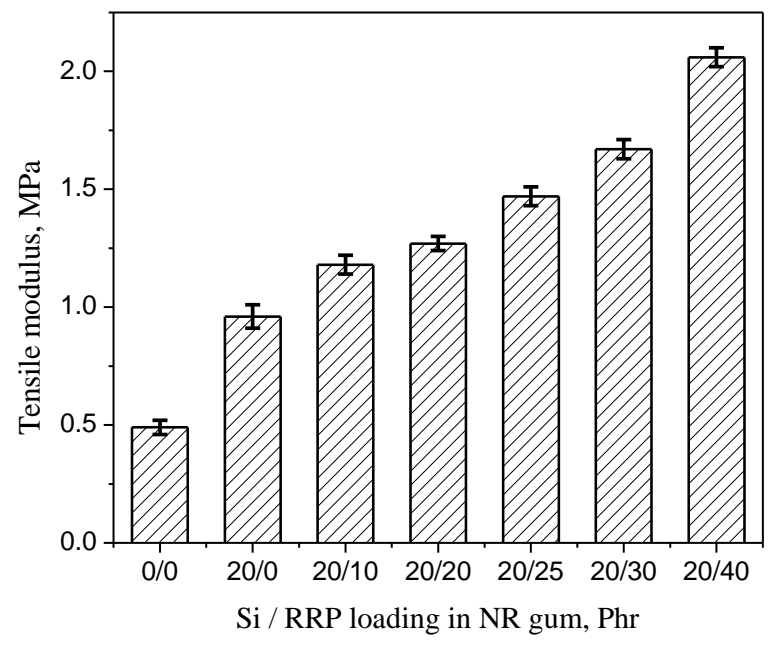

Fig. 4. Effect of tensile modulus variation with RRP loading

Hardness properties were studied for various proportions and the graph is given in Fig. 5. It can be seen that hardness gradually increases up to $30 \mathrm{phr}$ of RRP and then shows a slightly decreasing trend. It was due to better cross link density between the RRP and the rubber matrix. The presence of silica in the rubber matrix affects the hardness (After $30 \mathrm{phr}$ ). NR gum shows lesser hardness when compared with the $20 \mathrm{phr}$ of RRP.

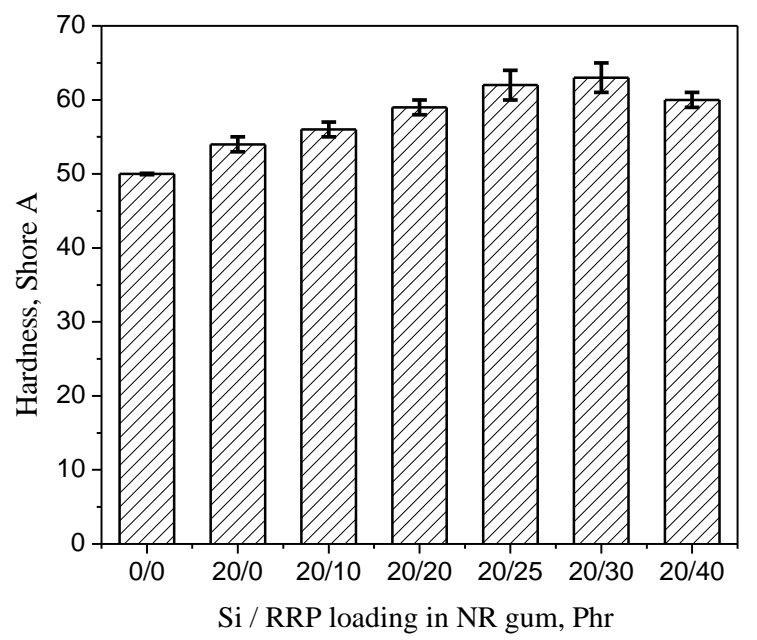

Fig. 5. Effect of hardness variation with RRP loading

The effect of tear strength on RRP is shown in Fig. 6. It can be seen that there is improvement up to $20 \mathrm{phr}$ of RRP and then is observed a decreasing trend. It is due to the crosslink density, filler type, and filler dispersion [13]. There could have been active cross linking sites / density existing due to fine filler and its proper dispersion till $20 \mathrm{phr}$ of RRP. Beyond this point higher amount of RRP dispersed non- uniformly with silica and rubber matrix and 
hence cross link density decreased, as tear strength decreased. NR gum shows lesser tear strength when compared with $20 \mathrm{phr}$ of RRP.

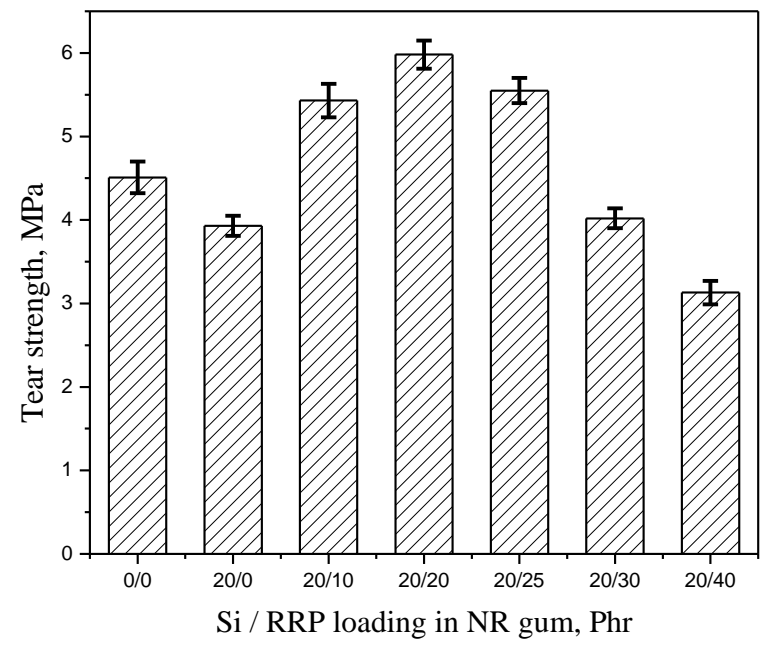

Fig. 6. Effect of tear strength variation with RRP loading

\subsection{Morphological observation}

The samples were observed with an SEM and the micrographs obtained have been shown in Fig. 7 - Fig. 10. Fig. 7 shows tensile fracture surface of NR gum and it can be seen that no cross link chains appear and no lack of homogeneity seen in the structure. Fig. 8 shows the tensile fracture surface of sample A. It can be seen that nonaddition of RRP into the Si-NR matrix caused many cross link chains to appear, which indicates higher tensile strength. It was due to nano silica particles getting dispersed uniformly in the NR matix and the resultant improved interfacial adhesion. Thus, silica filled natural rubber compounds have better tensile properties than those of RRP filled NR-Si vulcanizates. Fig. 9 and Fig. 10 show tensile fractured surface of sample D and F. It can be seen that partial filled RRP into the NR-Si compounds, the rubber particles were laid under the rubber compounds and not seen on the surface. So, it could be believed that interfaces between rubber matrix and RRP were enough to resist fractures and hence fracture occured through the bulk of rubber matrix, and not in the interfaces. A similar observation was reported by Sang-Woo Kim et al [18]. In sample F, large amount of RRP filled into the NR-Si compounds has caused detachment of RRP with the rubber compounds and poor interfacial adhesion. So, it weakens the mechanical properties. A non homogeneous structure is also observed besides poor bonding and hence tensile properties get decreased. However, H. Ismail et al., recorded maximum value of tensile strength observed with10 phr of RRP [9] and Petar S Dekic et al., reported that tear resistance could not be recommended beyond the limit of 5 phr of RRP [4]. Tensile strength and elongation at break had higher values compared with the devulcanized RRP with natural rubber, which was, perhaps, made possible due to presence of silica with RRP [17]. In this, minute RRP dispersed properly upto $25 \mathrm{phr}$ with NR$\mathrm{Si}$ compound and better tensile strength, Elongation at break, and tear strength within this range were observed.

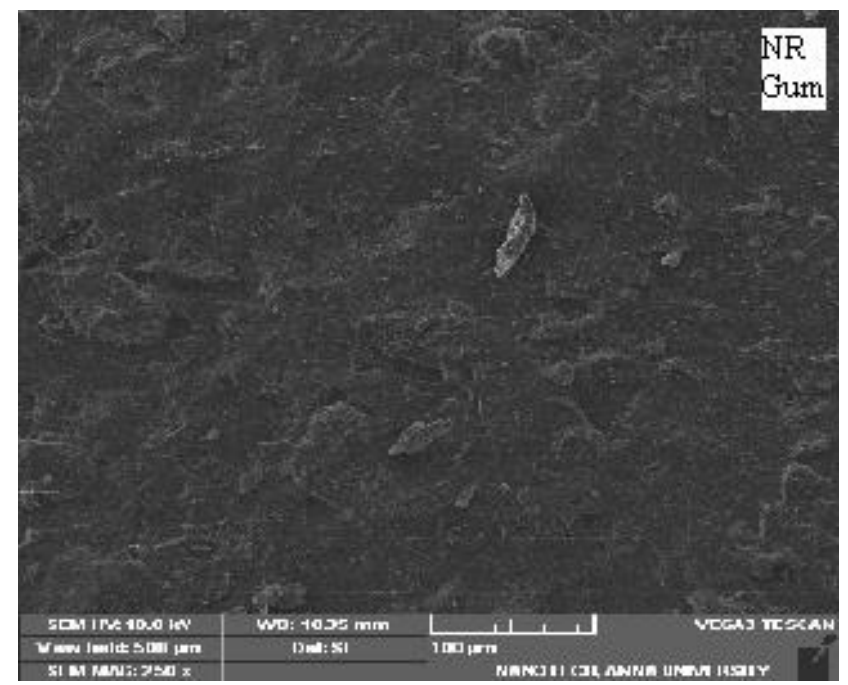

Fig. 7. Tensile fracture surface of natural rubber vulcanizates (NR gum-O sample)

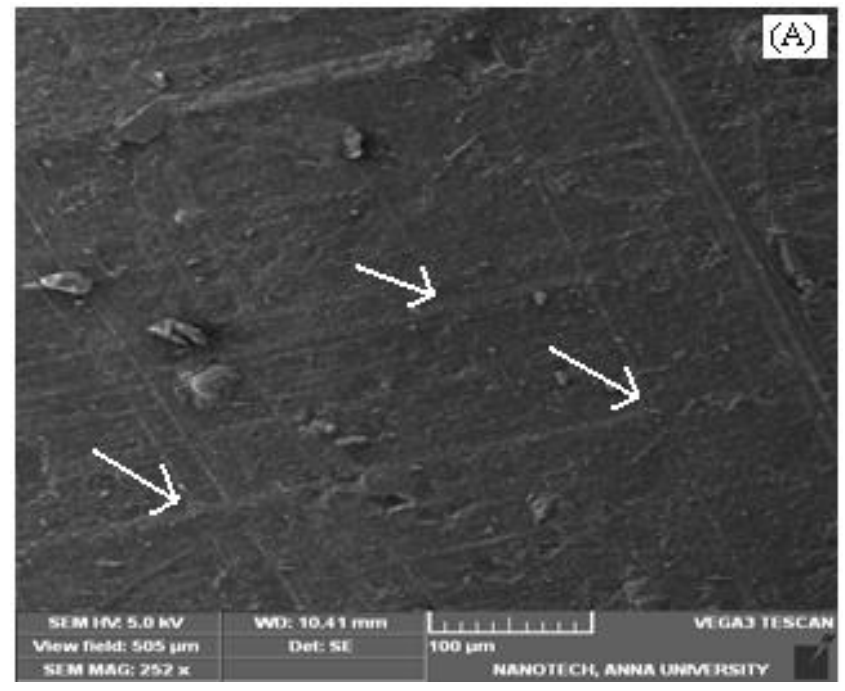

Fig. 8. Tensile fracture surface of natural rubber and silica compound with 0 phr of RRP

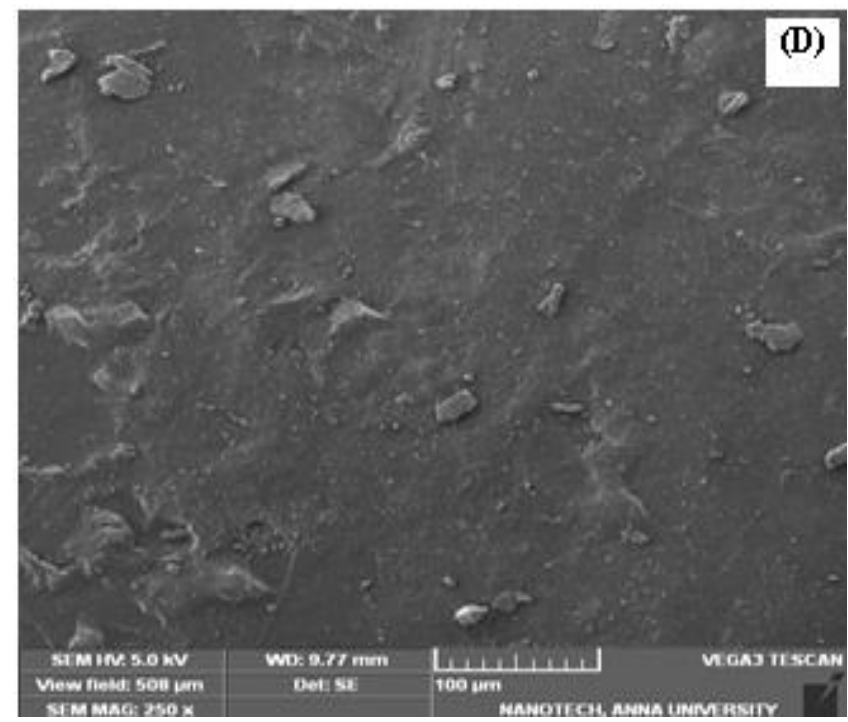

Fig. 9. Tensile fracture surface of natural rubber and silica compound with $25 \mathrm{phr}$ of RRP 


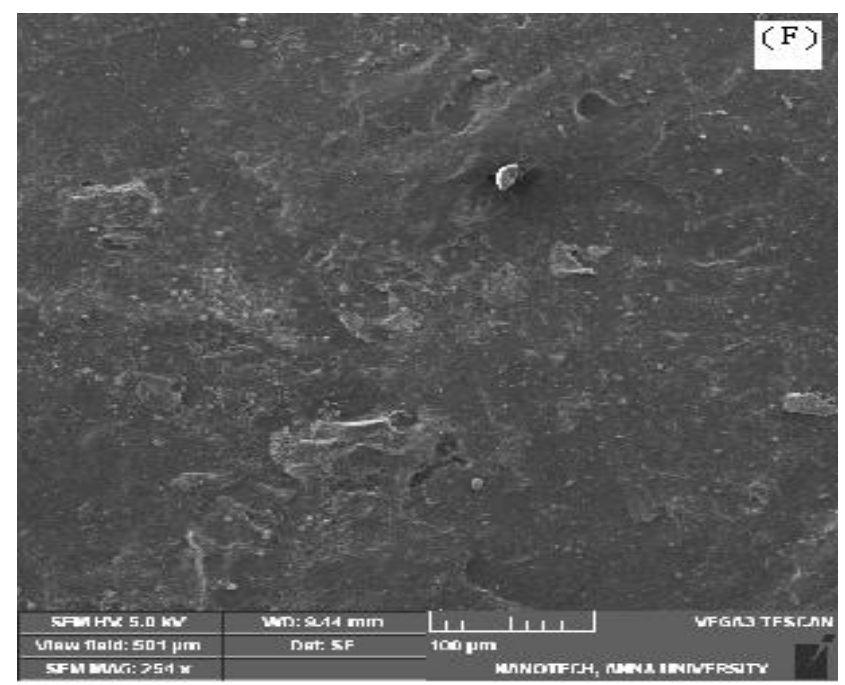

Fig. 10. Tensile fracture surface of natural rubber and silica compound with $40 \mathrm{phr}$ of RRP (Mag. 250X)

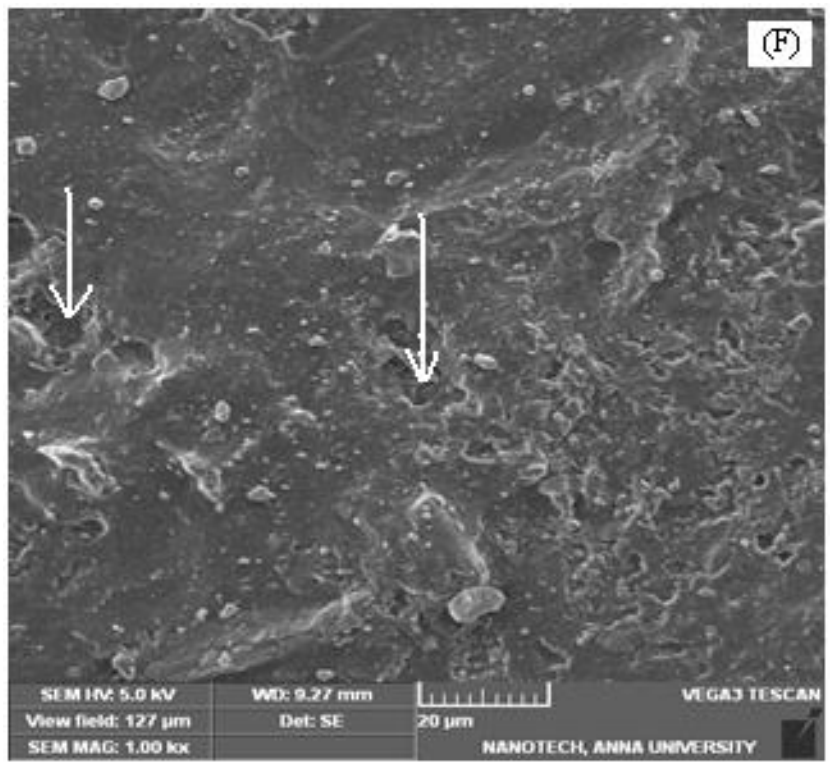

Fig. 11. Tensile fracture surface of natural rubber and silica compound with $40 \mathrm{phr}$ of RRP (Mag. 1.0KX)

\section{CONCLUSIONS}

Use of finely pulverised RRP and nano silica particles with natural rubber compounds causes enhancement in the properties. From this research work, the following conclusions can be drawn:

- Both tensile strength and elongation at break decrease gradually with increasing RRP loading but not tensile modulus.

- Hardness increases with the addition of the RRP loading up to $30 \mathrm{phr}$.

- Tear strength increases up to $20 \mathrm{phr}$ of RRP loading.

- Morphology study reveals that better filler dispersion and interfacial adhesion cause improved tensile strength and cross link density, filler type and dispersion result in higher tear strength.

- Incorporation of RRP and silica up to $20 \mathrm{phr}$ in NR did not loosening the performance of rubber articles. However, replacing RRP instead of carbon black in the rubber applications, leads to proper utilization of scrap rubber /worn out tyres.

- NR composite prepared with RRP minimizes the processing cost as well as usage of filler materials.

- Besides, RRP in NR-Si compounds improve the mechanical performance that could promote durability and reliability of rubber articles.

\section{Acknowledgements}

The authors are thankful to M/s. Supreme Rubber Industry, Coimbatore, India, where the experimental work was done and Central Institute of Plastics Engineering and Technology (CIPET), and College of Engineering, Guindy-Anna University, Chennai, India, where mechanical testing and SEM reports were carried out.

\section{REFERENCES}

1. Antoine, R., Luc, R., Robert, G. G. Synthesis and Properties of Composites of Starch and Chemically Modified Natural Rubber Polymer 45 (9) 2004: pp. 7813-7820.

2. Hanafi, I., Razif, N., Ahmed, M. N. The Effects of RRP Content and Various Vulcanization Systems on Curing Characteristics and Mechanical Properties of Natural Rubber /RRP Blends Iranian Polymer Journal 12 (5) 2003: pp. 373-380.

3. Yan, L., Yong, Z., Yinxi, Z. Mechanical Properties of HDPE /SRP Composite Modified with D.P.and Silicone oil Journal of Applied Polymer Science 88 (8) 2003: pp. $2020-2027$. http://dx.doi.org/10.1002/app.11907

4. Petar, S.-D., DragonI, T. Application of Recycled Rubber Powder(RRP) in NR / SBR Compounds Journal of Science \& Industrial Research 71 (3) 2012: pp. 295-298.

5. Mehmet, D., Demat, D. O. Physical Properties and Cure Characteristics of NR / Nanoclay Composites with Two Different Compatibilizers Journal of Applied Polymer Science 121 (3) 2011: pp. 1530-1535.

6. Kueseng, K., Jacob, K.-I. Natural Rubber Nanocomposites with SiC Nanoparticles and Carbon Nanotubes Europian Polymer Journal 42 (1) 2006: pp. 220-227.

7. Jana, H., Ivan, C., Peter, K. Modification and Characterization of Montmorillonite Fillers used in Composites with Vulcanized Natural Rubber Chemical Paper 63 (1) 2009: pp. 55-61.

8. Rattanasom, N., Prasertsri, S., Ruangritnumchai, T. Comparison of the Mechanical Properties at Similar Hardness Level of Natural Rubber Filled with Various Reinforcing-Fillers Polymer Testing 28 (1) 2009: pp. $8-12$.

http://dx.doi.org/10.1016/j.polymertesting.2008.08.004

9. Ismail, H., Nordin, R., Noor, A.-M. Cure Characteristics, Tensile Properties and Swelling Behaviour of Recycled Rubber Powder-Filled Natural Rubber Compounds Polymer Testing 21 (5) 2002: pp. 565-569. http://dx.doi.org/10.1016/S0142-9418(01)00125-8

10. Yuanbo, L., Li, L., Qi, W., Xin, Z. Fracture Properties of Natural Rubber Filled with Carbon Black and Nanoclay Journal of Polym Research 18 (5) 2011: pp. 859-867.

11. Findik, F., Yilmaz, R., Koksal, T. Investigation of Mechanical and Physical Properties of Several Industrial Rubbers Material Design 25 (4) 2004: pp. 269-274. 
12. Rajasekar, R., Kaushik, P., Gert, H. Development of Nitrile Butadiene Rubber - Nanoclay Composites with ENR as Compatibilizer Material Design 30 (9) 2009: pp. 3839-3845.

13. Gwaily, S.-E., Badawy, M.-M., Hassan, H.-H., Madani, M. Influence of Thermal Aging on Crosslinking Density of Boron Carbide/Natural Rubber Composites Polymr Testing 22 (1) 2003: pp. 3-7.

14. Seung, C.-H., Min, H.-H. Fracture Behavior of NR and SBR Vulcanizates Filled with Ground Rubber Having Uniform Particle Size Journal of Applied Polymer Science 85 (12) 2002: pp. $2491-2500$.

15. Krzysztof, F., Jozef, T. H. Curing characteristics, Mechanical Properties and Morphology of Butyl Rubber Filled with Ground Tire Rubber (GTR) Iranian Polymer Journal 23 (3) 2014: pp.185-194. http://dx.doi.org/10.1007/s13726-013-0214-7

16. Karger-Kocsis, J., Meszaros, L., Barany, T. Ground Tyre Rubber (GTR) in Thermoplastics, Thermosets and Rubbers Journal of Material Science 48 (1) 2013: pp. 1-38. http://dx.doi.org/10.1007/s10853-012-6564-2
17. Shuyan, L., Johanna, L., Kalle, H. Effect of Ground Rubber powder and Devulcanizates on the Properties of Natural Rubber Compounds Journal of Applied Polymer Science 97 (2) 2005: pp. 208-217.

18. Sang-Woo, K., Ki-Heon, H., Kwan-Ho, S. Effects of Ground Rubber Having Different Curing Systems on the Crosslink Structures and Physical Properties of NR Vulcanizates Material Research Innovation 7 (2) 2003: pp. 149-154.

19. Mihai, M., Schwarz, S., Janke, A. Silica Microparticles Surface Coating by Layer-By-Layer or Polyelectrolyte Complex Adsorption Polymer Research 20 (2) 2013: pp. 89-97.

20. Karabork, F., Pehlivan, E., Akdemir, A. Characterization of Styrene Butadiene Rubber and Microwave Devulcanized Ground Tire Rubber Composites Journal of Polymer Engineering 34 (60) 2014: pp. 10945-10954.

21. Milani, G ., Milani, F. Fast and Reliable Meta-Data Model for the Mechanistic Analysis of NR Vulcanized with Sulphur Polymer Testing 33 (1) 2014: pp. 64-78. 